\title{
An Approach towards Enterprise Architecture Analysis using AHP and Fuzzy AHP
}

\author{
M. Razavi Davoudi and K. Sheikhvand
}

\begin{abstract}
Enterprise Architecture (EA) as a discipline that manages large amount of models and information about different aspects of the enterprise can support decision making on enterprise-wide issues. In order to provide such support, EA information should be amenable to analysis of various utilities and quality attributes. In this regard, this paper provides an approach based on Fuzzy Analytical Hierarchy Process (AHP) towards EA analysis. It proposes an extended quantitative method of assessing quality attribute achievement of different scenarios using AHP and Fuzzy AHP based on the knowledge and experience of EA experts and domain experts. Due to the uncertainty in the judgments of participants, the crisp pair-wise comparison in the conventional AHP is insufficient and imprecise to capture the right judgments. Therefore, a fuzzy logic is introduced in the pair-wise comparison of AHP in one of steps of the method. The applicability of the proposed approach is demonstrated using a practical case study.
\end{abstract}

Index Terms-Enterprise architecture analysis, quality attribute, analytical hierarchy process, fuzzy logic, fuzzy AHP.

\section{INTRODUCTION}

Enterprises are complex, highly integrated systems comprised of processes, organizations, information and supporting technologies, with multifaceted interdependencies and interrelationships across their boundaries [1]. Taking a holistic approach, Enterprise Architecture focuses not only on the technical aspects but also on the various aspects of the enterprise upon which the IT systems operate [2]. Enterprise architecture analysis is the application of property assessment criteria on EA models. The purpose of conducting analysis of enterprise architecture models and information is to facilitate making rational decisions about information systems.

Our goal is to provide a framework to analyze EA scenarios, predict their levels of quality attributes achievement, based on related criteria, and assist decision making between them according to analysis results before implementing expensive enterprise-wide scenarios.

For this purpose, the following tasks need to be done: 1. To define and represent EA quality attributes explicitly [3]. 2. To provide a mechanism for assessing the level of quality attributes achievement in different EA scenarios.

The goal of this paper is to propose another quantitative assessment method of EA quality attribute achievement for

Manuscript received November 20, 2011, revised December 20, 2011.

M. Razavi Davoudi. is with the Islamic Azad University, Central Tehran Branch, Poonak, Tehran, Iran (e-mail: mah.razavi@iauctb.ac.ir).

K. Sheikhvand, was with Islamic Azad University, Central Tehran Branch, Poonak, Tehran, Iran. He is now with the Politecnico di Milano, Milan, Italy (e-mail: kourosh.sheykhvand@mail.polimi.it) different EA scenarios, based on the enterprise's situation with better result.

Caused by the fact that the evaluation process of EA scenario candidates is a multiple-criteria decision-making (MCDM) problem in the presence of many criteria and alternatives, a decision-maker(s) needs to use one of current MCDM methods. One such MCDM technique, AHP [4,5], is leveraged in this method for prioritizing and selecting a desired architecture scenario among candidates. Different methods may be applied for prioritization [6]. This includes subjective judgment with or without consensus building and methods such as providing a total sum of points to be divided between the items or aspects you would like to prioritize. Most methods have however weaknesses and it is mostly hard to judge the goodness of the prioritization. AHP addresses some of these problems [4], since it allows for a calculation of a consistency index for the prioritization. This opportunity arises from the fact that AHP is based on all pair-wise comparisons of whatever we would like to prioritize. Also this fact causes more accurate results of AHP than other methods [7]. AHP is qualitative and easier to implement from both a data requirement and validation point of view [8]. The method is appropriate for evaluation of quantitative and qualitative related attributes and using the AHP means that not all independence conditions of the MAUT need to be verified, nor utility functions derived [8]. AHP's popularity stems from its simplicity, flexibility, intuitive appeal as well as its ability to mix quantitative and qualitative criteria in the same decision framework.

One drawback of AHP that should be considered is its inability in solving uncertain decision-making problems. In fact, in standard AHP, human's judgments are represented as exact (or crisp) numbers. However, in many practical cases, the human preference model is uncertain and decision-makers might be reluctant or unable to assign exact numerical values to the comparison judgments $[8,9]$.

The case study which is used in this paper is an abbreviated version of a study under development in Ports and Maritime Organization of Iran (PMO). This is done to give a more comprehensive presentation of how the method can be used and to demonstrate the efficacy of our approach.

The remainder of the paper is outlined as follows:

In section 2, the related work to this paper and the differences between them are described. Section 3 is devoted to an introduction to AHP and Fuzzy AHP and also the explanation of the proposed analysis method in a step by step manner. Also in this section, a case study is presented where the proposed method is used in a step by step manner. Finally in section 4 the paper is concluded and future work are introduced. 


\section{RELATED WORK}

The related work to this paper consists of 3 groups:

1. Software quality attributes measurement methods based on MCDM methods [10], [11], [12], [13], [14] we have used the idea of some of these methods in our analysis approach.

2. The analysis methods in the EA community including [2] [15], [16], [17], [18], [19], [20], [21], [22], [23], [24].

The main contributions of our approach which make it different from the approaches of group 2 are as below:

a) In our approach, the criteria and sub-criteria of a quality attribute are given different weights according to the EA layers each of them belong to and also the importance of each EA layer in the enterprise. Above mentioned approaches, use causal effect and probability theory, and model causal probabilities between quality attributes and criteria.

b) Through our approach, we use the knowledge and experience of two groups of experts in our assessment; EA experts and domain experts. This ensures a broader decision base according to different points of view and allows identification of differences in experiences.

c) All above methods use formal languages such as Influence Diagrams or their extended version to support the analysis of EA, but we have used Analytical Hierarchy Process (AHP) as a multi criteria decision making method, which is the first experience of using this method in the field of EA analysis.

3. There are some similar EA analyses approaches which are based on the same idea of this paper; References [25][26] and the most completely presented approach [27] have not used fuzzy in the EA analysis approach. Also [28] contains the idea of using fuzzy AHP in the EA analysis approach but the approach is less mature with less detail.

\section{THE PROPOSED METHOD}

The aim of this paper is to provide a method to facilitate deciding between different scenarios according to their level of quality attribute achievement. This method is usable after gathering complete information about the current EA of the enterprise. In this approach, each quality attribute is composed of several criteria and sub-criteria which are specified in the quality attribute general scenario [3]. This includes subjective judgment with or without consensus building and methods such as providing a total sum of points to be divided between the items you would like to prioritize. This opportunity arises from the fact that AHP is based on all pair-wise comparisons.

To better understand the proposed approach, we first precisely describe AHP and Fuzzy AHP methods used in this paper, and then explain the proposed approach in a step by step manner (Fig. 1). In this figure the yellow boxes represent the steps that directly use AHP and the green box represent the step that uses Fuzzy AHP.

\section{A. Analytical Hierarchy Process (AHP) and Fuzzy AHP}

AHP consists of a set of steps, where all combinations of elements are evaluated pair-wise, and according to a certain scale (Fig. 2). The question to answer for each pair-wise comparison is which of the two elements, $\mathrm{i}$ or $\mathrm{j}$ is more important, and how much more important is it? This is rated by interpreting the values as presented in Table I. For more detail about AHP approach, please refer to [27] [28] [4] [5]. In this study, triangular fuzzy numbers, $\tilde{1}_{\text {to }} \tilde{9}$, are used to represent subjective pair-wise comparisons of selection process (equal to extremely preferred) in order to capture the vagueness and imprecision of human qualitative assessments.

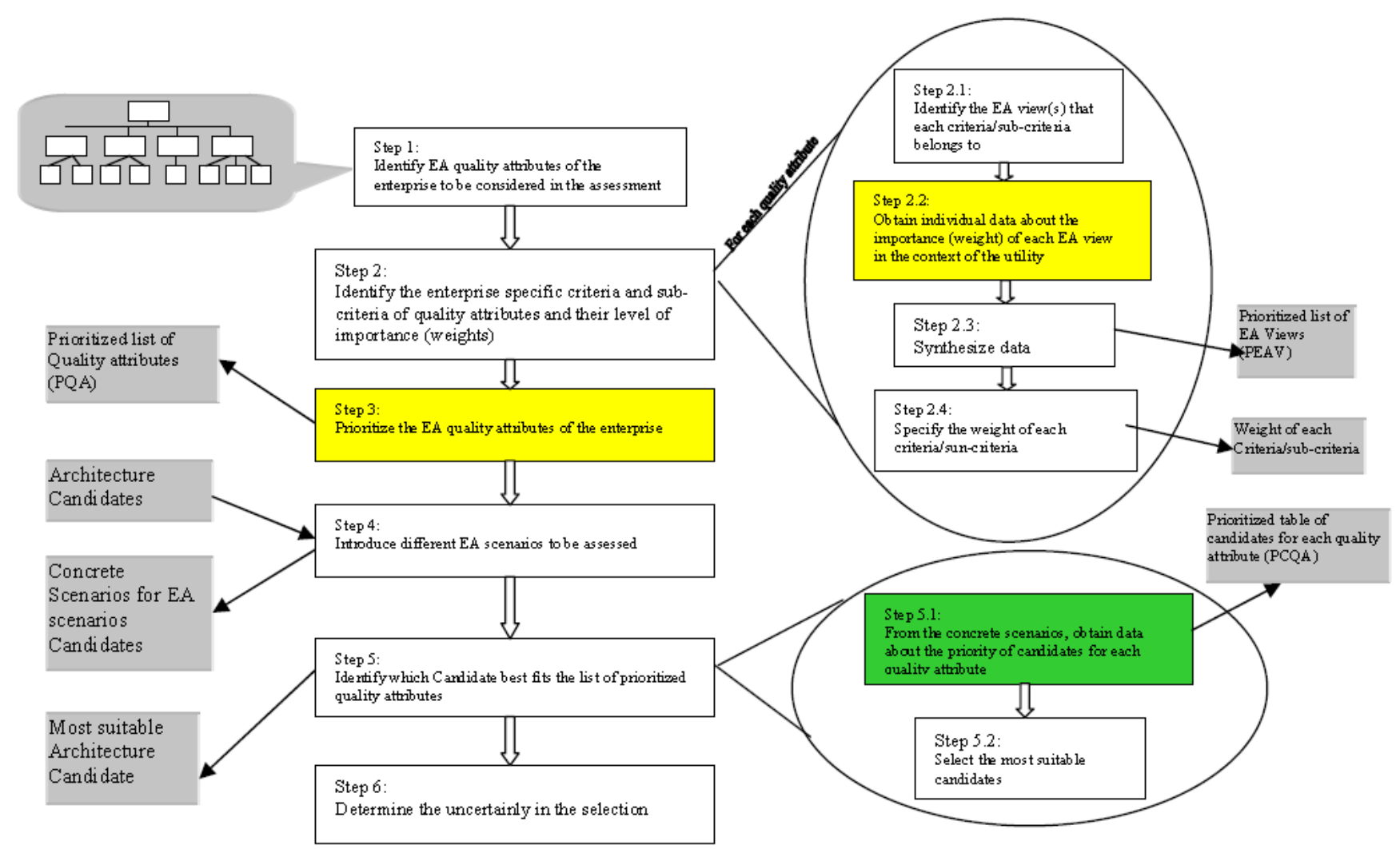

Fig. 1. Illustration of Solution 


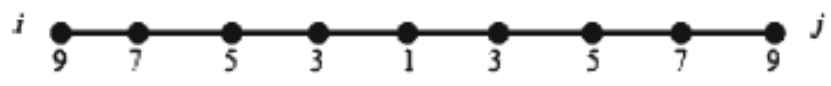

Fig. 2. The scale for the AHP comparison

TABLE I: SCALE FOR PAIRWISE COMPARISON USING AHP [4][ 5]

\begin{tabular}{|l|l|l|}
\hline \multicolumn{1}{|c|}{$\begin{array}{c}\text { Relative } \\
\text { Intensity }\end{array}$} & \multicolumn{1}{|c|}{ Definition } & \multicolumn{1}{c|}{ Explanation } \\
\hline 1 & Of equal importance & $\begin{array}{l}\text { The two variables (i and j) are of } \\
\text { equal importance }\end{array}$ \\
\hline 3 & $\begin{array}{l}\text { Slightly more } \\
\text { important }\end{array}$ & $\begin{array}{l}\text { One variable is Slightly more } \\
\text { important than the other }\end{array}$ \\
\hline 5 & $\begin{array}{l}\text { Highly more } \\
\text { important }\end{array}$ & $\begin{array}{l}\text { One variable is highly more } \\
\text { important than the other }\end{array}$ \\
\hline 7 & $\begin{array}{l}\text { Very highly more } \\
\text { important }\end{array}$ & $\begin{array}{l}\text { One variable is very highly more } \\
\text { important than the other }\end{array}$ \\
\hline 9 & $\begin{array}{l}\text { Extremely more } \\
\text { important }\end{array}$ & $\begin{array}{l}\text { One variable is extremely more } \\
\text { important than the other }\end{array}$ \\
\hline $2,4,6,8$ & $\begin{array}{l}\text { Immediate values } \\
\text { Reciprocal }\end{array}$ & $\begin{array}{l}\text { Used when compromising between } \\
\text { the other numbers }\end{array}$ \\
\hline & $\begin{array}{l}\text { If variable i has one of the above numbers assigned to it } \\
\text { when compared with variable } \mathrm{j}, \text { then } \mathrm{j} \text { has the value } \\
1 / \text { number assigned to it when compared with i. }\end{array}$ \\
\hline
\end{tabular}

Five triangular fuzzy numbers are defined this way: 1 is Equally important, 2 is Moderately more important, 3 is Strongly more important, 4 is Very strongly more important, and 5 is Extremely more important. Fuzzy membership function for linguistic values is depicted in Fig. 3.

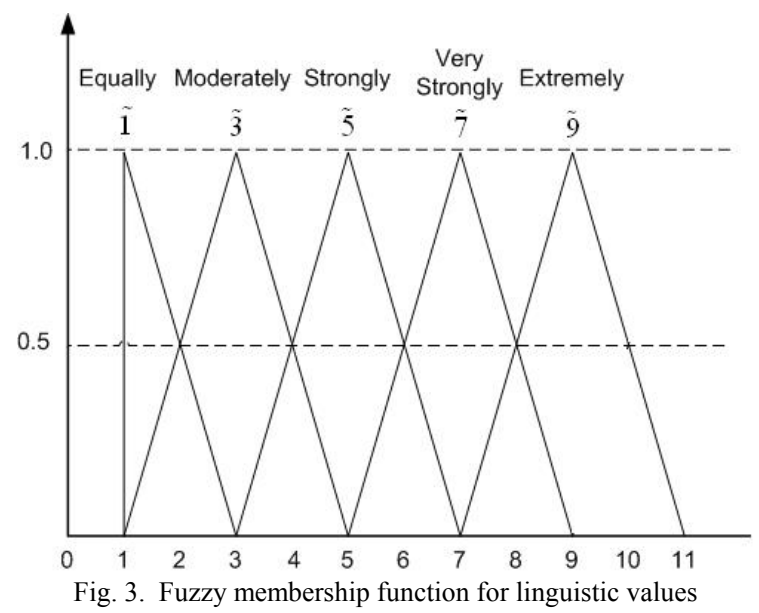

By using triangular fuzzy numbers, the decision-maker(s) are asked to respond to a series of pair-wise comparisons with respect to an upper level "control" criterion. These are conducted with respect to their relevant importance towards the control criterion. Then, the fuzzy judgment matrix, $\mathrm{A}\left(\tilde{a}_{i j}\right)$ is constructed via pair-wise comparison:

$$
A=\left[\begin{array}{ccccc}
1 & \tilde{a}_{12} & \cdots & \cdots & \tilde{a}_{1 n} \\
\tilde{a}_{21} & 1 & \cdots & \cdots & \tilde{a}_{2 n} \\
\vdots & \vdots & \vdots & \vdots & \vdots \\
\tilde{a}_{n 1} & \tilde{a}_{n 2} & \cdots & \cdots & 1
\end{array}\right]
$$

where $\tilde{a}_{i j}=1$, if $\mathrm{i}$ is equal to $\mathrm{j}$, and $\tilde{a}_{i j}=\tilde{1} ; \tilde{3} ; \tilde{5} ; \tilde{7} ; \tilde{9}$ or $\tilde{1}^{-1} ; \tilde{3}^{-1} ; \tilde{5}^{-1} ; \tilde{7}^{-1} ; \tilde{9}^{-1}$, if $\mathrm{i}$ is not equal to $\mathrm{j}$.

When scoring is done for a pair, a reciprocal value is automatically assigned to the reverse comparison within the matrix [4]. Alternatively, by defining the interval of confidence level $\alpha$, the triangular fuzzy number can be characterized using the following equation:

$$
\forall \alpha \in[0,1] M_{\alpha}=\left[l^{\alpha}, u^{\alpha}\right]=[(m-l) \alpha+l,-(u-m) \alpha+u]
$$

With fixed $\alpha$, the index of optimism, $\mu$, can be set in order to estimate the degree of satisfaction and the following judgment matrix can be obtained. The eigenvector is calculated by fixing the $\mu$ value and identifying the maximal eigenvalue.

$$
\tilde{A}=\left[\begin{array}{ccccc}
1 & \tilde{a}_{12}^{\alpha} & \cdots & \cdots & \tilde{a}_{1 n}^{\alpha} \\
\tilde{a}_{21}^{\alpha} & 1 & \cdots & \cdots & \tilde{a}_{2 n}^{\alpha} \\
\vdots & \vdots & \vdots & \vdots & \vdots \\
\tilde{a}_{n 1}^{\alpha} & \tilde{a}_{n 2}^{\alpha} & \cdots & \cdots & 1
\end{array}\right]
$$

where $\alpha$-cut is known to incorporate the experts or decision-maker(s) confidence over his/her preference or the judgments.

Degree of satisfaction for the judgment matrix is estimated by the index of optimism $\mu$ determined by the decision-maker. The larger value of index $\mu$ indicates the higher degree of optimism. The index of optimism is a linear convex combination as defined in the following equation:

$$
\tilde{a}_{i j}^{\alpha}=\mu a_{i j u}^{\alpha}+(1-\mu) a_{i j l}^{\alpha}, \quad \forall \mu \in[0,1]
$$

Once the pair-wise comparisons are completed, the local priority vector $\mathrm{w}$ (also referred as e-Vector) is computed as the unique solution using the following equation:

$$
A w=\lambda_{\max } w
$$

where $\lambda_{\max }$ is the largest eigenvalue of $\mathrm{A}$.

After constructing all required pair-wise judgment matrices between criteria and alternatives levels, for each, $\mathrm{CR}$ and $\mathrm{CI}$ should be calculated:

\section{B. Steps of the proposed approach}

In the proposed framework, AHP is used in steps 2.2, 3 and Fuzzy AHP is used in step 5.1. In all three steps, CR must be computed. Whenever $\mathrm{CR}$ is more than $10 \%$, pair-wise comparison should be done again with more precise information. Below, we describe each step and the way each step is applied in the case study. Our case study is conducted in Ports \& Maritime Organization of Iran (PMO).

\section{Step 1: Identify EA quality attributes of the enterprise to be considered in the assessment;}

The important quality attributes of the enterprise that affect the selection of EA scenarios should be specified.

For PMO, at the time of our study, the important EA quality attribute was maintainability. Detailed definition of EA maintainability is presented in [3].

Step 2: Identify the enterprise-specific criteria and subcriteria of quality attributes and their level of importance (weight);

Each EA quality attribute is characterized by some criteria and sub-criteria [3]. We have proposed an approach to specialize quality attribute criteria and sub-criteria according to the areas of focus in the enterprise. EA frameworks typically consist of four architectural views: business architecture (BA), data architecture (DA), software architecture (SA) and technology architecture (TA). In this approach, as described by the following steps, each criteria and sub-criteria of a quality attribute is given a weight 
according to the enterprise architectural views it relates to and the importance of EA views in the enterprise.

\section{Step 2.1: Identify the EA view that each criteria/sub- criteria belongs to;}

In this step an EA expert should specify the EA view(s) that each criteria/sub-criteria belongs to.

In PMO case study, according to an EA expert's opinion, the EA view(s) that maintainability criteria belong to are presented in Table II.

TABLE II: EA MAINTAINABILITY CRITERIA AND SUB-CRITERIA AND THEIR RELATED EA VIEWS

\begin{tabular}{|l|c|}
\hline \multicolumn{1}{|c|}{ Criteria/sub-criteria } & $\begin{array}{c}\text { Related EA } \\
\text { view }\end{array}$ \\
\hline Quality of Maintenance Policy and its sub-criteria & BA \\
\hline $\begin{array}{l}\text { Maturity of EA Development and Maintenance Personnel } \\
\text { and its sub-criteria }\end{array}$ & BA \\
\hline $\begin{array}{l}\text { Maturity of EA Development and Maintenance Processes } \\
\text { and its sub-criteria }\end{array}$ & BA \\
\hline Quality of Supporting Documentation and its sub-criteria & All views \\
\hline Business Architecture Quality and its sub-criteria & BA \\
\hline Data Architecture Quality and its sub-criteria & DA \\
\hline Software Architecture Quality and its sub-criteria & SA \\
\hline Quality of Source code & SA \\
\hline Technology Architecture Quality and its sub-criteria & TA \\
\hline
\end{tabular}

Step 2.2: Obtain Individual data about the importance (weight) of each EA view in the context of the utility;

Regarding AHP method in this step, weight of EA views should be assigned by pair-wise comparison e.g. by questionnaire. So, a questionnaire is designed for each quality attribute, which contains a description of that quality attribute in each EA view. For this purpose, the most important and tangible criteria of the quality attribute related to each EA view are described. Then some of the main experts of the enterprise are asked to fill the questionnaire and do pairwise comparison between the EA views. The outcome of this step using AHP is one vector per participant with relative weights on the importance of each EA view in the enterprise.

\section{Step 2.3: Synthesize data;}

The median value of the individual vectors produced in the previous step, is then used to create a single vector, called PEAV (Prioritized list of EA Views). This vector represents the weight of each EA view in the context of the quality attribute in the enterprise. In PMO, the result of this step for maintainability is illustrated in Table III. Each vector is the median value of the ten individual vectors produced in the previous step.

TABLE III: THE WEIGHT OF EA VIEWS IN THE CONTEXT OF MAINTAINABILITY IN PMO

\begin{tabular}{|l|l|}
\hline Architecture View & Weight \\
\hline Business Architecture view & 0.54551 \\
\hline Data Architecture view & 0.291808 \\
\hline Software Architecture view & 0.107078 \\
\hline Technology Architecture view & 0.055604 \\
\hline
\end{tabular}

Step 2.4: Specify the weight of each criteria/sub-criteria;

The weight of each criteria/sub-criteria of the quality attribute is equal to the weight of the EA view which it relates to and:
- If a criteria/sub-criteria relates to more than one EA view, then its weight will be the maximum weight of the EA views.

- If the weight of a criteria/sub-criteria is zero, then the criteria/sub-criteria and all its sub-criteria should be omitted.

As the result of conducting this step in our case study, Table IV is produced.

TABLE IV: WEIGHT OF EACH CRITERIA OF MAINTAINABILITY IN PMO

\begin{tabular}{|l|l|}
\hline Criteria/Sub-criteria & Weight \\
\hline Quality of Maintenance Policy & 0.54551 \\
\hline $\begin{array}{l}\text { Maturity of EA Development and Maintenance Personnel } \\
\text { and its sub-criteria }\end{array}$ & 0.54551 \\
\hline $\begin{array}{l}\text { Maturity of EA Development and Maintenance Processes } \\
\text { and all its sub-criteria }\end{array}$ & 0.54551 \\
\hline $\begin{array}{l}\text { Quality of Supporting Documentation and all its } \\
\text { sub-criteria }\end{array}$ & 0.54551 \\
\hline Business Architecture Quality and all its sub-criteria & 0.54551 \\
\hline Data Architecture Quality and all its sub-criteria & 0.291808 \\
\hline Software Architecture Quality and all its sub-criteria & 0.107078 \\
\hline Technology Architecture Quality and all its sub-criteria & 0.055604 \\
\hline
\end{tabular}

Step 3: Prioritize the EA quality attributes of the enterprise for this purpose; we use the opinion of domain experts of the enterprise.

The outcome of this step is one vector per participant with relative weights on the importance of the different quality attributes for the EA of the enterprise. The median value of these individual vectors is then used to create a single vector, called PQA (Prioritized list of Quality Attributes).

For simplicity in representing the method, in our case study we have specified only one quality attribute, so we skip this step for PMO.

\section{Step 4: Introduce different EA scenarios (candidates) to be assessed;}

In this step, different EA scenarios should be described completely so that participants understand the differences and similarities between them. Then for each EA scenario candidate a concrete scenario is created. As mentioned in [3], a general scenario is a data structure containing general information about each EA quality attribute. For each EA quality attribute general scenario, multiple concrete scenarios can be provided. Concrete scenarios are instances of general scenarios. Each concrete scenario corresponds to an EA quality attribute requirement in a specified EA scenario candidate. Concrete scenarios have the same 7 elements as general scenarios, but each concrete scenario element is a subclass of the corresponding general scenario element meaning that concrete scenario element instances are a subset of general scenario element instances. Each instance of measure in a concrete scenario takes a value which represents the effect of the value of the corresponding.

EA quality attributes measure in an EA scenario candidate, on the related quality attribute. Creating a concrete scenario for an EA scenario candidate, should be done by aggregating the ideas of a group of EA experts. Two options exist:

- Group of participants act as a unit by performing focused discussions to create a joint understanding of the EA scenario candidate. The output of step 4 using this option is one concrete scenario, which contains the aggregated ideas of a group of EA experts. 
- $\quad$ Each participant acts as a separate individual and creates a concrete scenario, and then all individual concrete scenarios will be aggregated into one concrete scenario. The second option, applies where experts have significantly different opinions and a consensus on judgments cannot be reached. Here a group synthesis is obtained but an additional aggregation procedure for combining the individual concrete scenarios into a group concrete scenario is required. The group synthesis is commonly achieved by applying Weighted Average Mean technique (WAM).

Here we use a composite of the two options to create an aggregate concrete scenario. One of the elements which contain the related measures and their values is aggregated by applying WAM (Weighted Average Mean) technique and other elements are aggregated by performing discussions.

In PMO, in recent years, one of the main concerns was the strategy of providing human resources for business process maintenance.

They had two EA scenario candidates to choose from:

1. To hire external consultants to carry out their business process re-engineering and maintenance. In this scenario, they could use the services of a professional consultant from the date of contract. PMO just needs a role to gather the requests of business process change and improvement and transfer them to the consultant. The consultant would then design or improve the business processes, record them in the related software platform and update the required documentation.

2. To employ and train business process analysts in PMO for ongoing maintenance and reengineering of business processes. In this scenario, an organizational unit should be defined for business process engineering. Some employees should be provided. They could be non-professional employees who should be trained for this purpose, or some professional employees. Of course the latter has higher ongoing cost. In this scenario, any request for business process change or improvement can be implemented instantly.

In this step of applying the approach to the case study, for each EA scenario candidate a concrete scenario is created. Table $\mathrm{V}$ demonstrates the measures of the first candidate scenario and their values. It should be noted that if measure is not indicated in the table, it means that in the candidate scenario, the measure has no effect on the quality attribute.

TABLE V: EA MAINTAINABILITY MEASURES AND VALUE OF THE CONCRETE SCENARIO EXTRACTED FOR THE FIRST EA SCENARIO CANDIDATE

\begin{tabular}{|l|l|}
\hline Measure (criteria/sub-criteria) & Value \\
\hline Cost of maintenance policy & -1.6 \\
\hline Risk (of continuous service) & -1 \\
\hline Risk (of high quality work) & 1 \\
\hline Staff level of experience & -0.6 \\
\hline Staff level of EA knowledge & -0.8 \\
\hline Consistency of documentation & -0.8 \\
\hline Modifiability of documentation & -1 \\
\hline $\begin{array}{l}\text { Business Architecture Quality-Traceability to other } \\
\text { EA components }\end{array}$ & -1 \\
\hline
\end{tabular}

Step 5: Identify which candidate best fits the list of prioritized quality attributes;

In this step, to assess and prioritize the EA scenarios, we asked 5 experts to give their ideas.
Step 5.1: From the concrete scenarios, obtain data about the priority of candidates for each quality attribute;

For this purpose, first we normalized the weights of the leaf sub-criteria of the criteria/sub-criteria hierarchy of maintainability [26]. Then, for each of the leaf nodes in these criteria/sub-criteria hierarchy, the values of the corresponding measures in concrete scenarios are compared in a pair-wise manner and one of the five triangular fuzzy numbers $(\tilde{1} ; \tilde{3} ; \tilde{5} ; \tilde{7} ; \tilde{9})$ are assigned to express the preference in the pair-wise comparisons.

Value of $\alpha$ and $\mu$ are determined and each cell of the matrix will be computed according to Eq. (4) and as explained before, the consistency index of each generated comparison matrix should be checked.

The outcome of the prioritization process in this step is one vector (PCQA) containing priority of the EA scenarios according to EA quality attributes of the enterprise.

In this case study we determined $\alpha=0.5$ and $\mu=0.5$ and checked the consistency of all matrices. Table VI illustrates PCQA of PMO.

TABLE VI: PCQA OF PMO FOR EA MAINTAINABILITY
\begin{tabular}{|l|l|}
\hline EA Scenario & Weight \\
\hline EA Scenario1 & 0.4 \\
\hline EA Scenario2 & 0.6 \\
\hline Sum & 1 \\
\hline
\end{tabular}

\section{Step 5.2: Select the most suitable candidate;}

Level of Suitability of each EA scenario candidate for PMO:

Level of Suitability of EA scenario $1=0.4$

Level of Suitability of EA scenario $2=0.6$

Step 6: Determine the uncertainty in the selection;

Here we had only two scenarios to choose from, so the VAR vector has identical elements as shown in Table VII:

TABLE VII: THE VARIANCE OF PCQA

\begin{tabular}{|l|l|}
\hline EA Scenario & Variance \\
\hline EA Scenario1 & 0.010776 \\
\hline EA Scenario2 & 0.010776 \\
\hline
\end{tabular}

In this example, we considered only one quality attribute, so the uncertainty of our selection is identical to the VAR vector and is equal to 0.01 which represents that the results are acceptable.

\section{CONCLUSION AND FUtURE WORK}

In this paper we present a quantitative assessment method of EA quality attribute achievement for different EA scenarios, based on the enterprise's situation. This method can be used to indicate the architecture candidates that best suits the quality attributes of a given EA. This can then be used to hold focused discussions on areas where there are disagreements, between participants of the assessment, to increase the confidence that the correct decision is taken.

At the end the method calculates the uncertainty related to the selection.

One major benefit of the method, besides other benefits 
[27], is that it can be automated by software which facilitates knowledge management and decision making in the enterprise. We have developed a software tool for this purpose.

As future work we can introduce the use of Fuzzy AHP in other steps of decision making in the proposed approach. Also Analytical Network Process (ANP) as another MCDM method can be used in EA Analysis. This method considers the interdependencies between hierarchy nodes and creates a network of nodes. This contradicts with AHP that considers each node independently.

As another future work, we can add sensitivity analysis to the proposed approach. One of the drawbacks of AHP is that the produced ranking can be sensitive such that the smallest change in intermediate priority weights can alter the final order of design alternatives.

\section{REFERENCES}

[1] D.J. Nightingale and D.H. Rhodes, "Enterprise Systems Architecting: Emerging Art and Science within Engineering Systems", presented at the MIT Engineering Systems Symposium: 2004.

[2] F.J. Armour, S.H. Kaisler and S.Y. Liu, "Building an enterprise architecture step by step", IEEE IT Professional, vol. 1, no 4, pp.31-39, 1999.

[3] M. Razavi and F. Shams Aliee, "Characterization of Enterprise Architecture Quality Attributes", in Proc. 13th Enterprise Distributed Object Computing Conference Workshops (EDOCW 2009), NewZealand, 2009, pp. 131-137.

[4] T. L. Saaty, The Analytic Hierarchy Process, McGraw Hill, Inc., New York NY, 1980

[5] T.L. Saaty and L.G. Vargas, Models, Methods, Concepts \& Applications of the Analytic Hierarchy Process, Kluwer Academic Publishers, Dordrecht, the Netherlands, 2001.

[6] J. Karlsson,C. Wohlin and B. Regnell, "An evaluation of methods for prioritizing software requirements", Information and Software Technology, vol. 39, no. 14-15, pp. 938-947, 1998.

[7] A. Seyed Danesh and R. Ahmad, "Study of prioritization techniques using students as subjects" In Proc. the international conference on information management and engineering (ICIME), 2009, pp. 390-394.

[8] H. Deng, "Multicriteria analysis with fuzzy pairwise comparisons", International Journal of Approximate Reasoning, vol. 21, pp. 215-231, 1999.

[9] L. Mikhailov and P. Tsvetinov, "Evaluation of services using a fuzzy analytic hierarchy process", Applied Software Computing, vol. 5, pp. 23-33, 2004

[10] T. Al-Naeem, I. Gorton, M. A. Babar, F. Rabhi and B. Benatallah, "A quality-driven systematic approach for architecting distributed software applications", presented at the 27th International Conference on Software Engineering (ICSE), St. Louis, USA, 2005.

[11] M. Svahnberg, C. Wohlin, L. Lundberg, M. Mattsson, "A quality-driven decision-support method for identifying software architecture candidates", International Journal of Software Engineering and Knowledge Engineering, vol. 13, no. 5, pp. 547-573, 2003.

[12] M. Svahnberg, C. Wohlin, L. Lundberg and M. Mattsson, "A method for understanding quality attributes in software architecture structures", In Proc. 14th international conference on Software engineering and knowledge engineering (SEKE), 2002, pp. 819-826.

[13] L. Zhu, A. Aurum, I. Gorton and D. Jeffery, "Tradeoff and Sensitivity Analysis in Software Architecture Evaluation Using Analytic Hierarchy Process", Software Quality Journal, vol. 13, no. 4, pp. 357-375, 2005.

[14] A. Reddy, M. Naidu and P. Govindarajulu, "An Integrated approach of Analytical Hierarchy Process Model and Goal Model (AHP-GP Model) for Selection of Software Architecture", International journal of Computer Science and Network Security, vol. 7, no. 10, pp. 108-117, 2007.

[15] P. Närman, P. Johnson and L. Nordström, "Enterprise Architecture: A Framework Supporting System Quality Analysis", In Proc. 11th IEEE Enterprise Distributed Object Computing Conference, 2007, pp. $130-141$.
[16] P. Johnson, R. Lagerström, P. Närman and M. Simonsson, "Extended Influence Diagrams for Enterprise Architecture Analysis", In Proc. 10th IEEE Enterprise Distributed Object Computing Conference, 2006, pp. 3-12.

[17] P. Johnson, R. Lagerström, P. Närman and M. Simonsson, "Extended Influence Diagrams for System Quality Analysis", Journal of Software (JSW), vol. 2, no. 3, pp. 30-42, 2007.

[18] R. Lagerström, "Analyzing System Maintainability Using Enterprise Architecture Models", In Proc. 2nd Workshop on Trends in Enterprise Architecture Research (TEAR'07), St Gallen, Switzerland, 2007, pp. 31-39.

[19] P. Johnson, E. Johansson, T. Sommestad and J. Ullberg, "A Tool for Enterprise Architecture Analysis", In Proc. 11th IEEE Enterprise Distributed Object Computing Conference, 2007, pp. 142-156.

[20] P. Johnson, R. Lagerström, P. Närman and M. Simonsson, "Enterprise architecture analysis with extended influence diagrams", Information Systems Frontiers, vol. 9, no. 2-3, pp. 163-180, 2007.

[21] F. S. Boer, M. M. Bonsangue, J. Jacob, A. Stam and L. van der Torre, "Enterprise architecture analysis with XML", In Proc. 38th Annual Hawaii International Conference on System Sciences (HICSS 2005). Vol. 8, USA, IEEE Computer Society Press, 2005.

[22] M. E. Jacob and H. Jonkers, "Quantitative analysis of enterprise architectures", In Konstantas, D., Bourrieres, J.P., Leonard, M., Boudjlida, N., eds.: Interoperability of Enterprise Software and Applications, Geneva, Switzerland, Springer, 2006, pp. 239-252.

[23] K. D. Niemann, From Enterprise Architecture to IT GovernanceElements of Effective IT Management, Vieweg+Teubner, Wiesbaden, Germany, 2006

[24] E. Yu, M. Strohmaier and X. Deng, "Exploring intentional modeling and analysis for enterprise architecture", presented in the EDOC 2006 Conference Workshop on Trends in Enterprise Architecture Research (TEAR 2006), Hong Kong, 2006.

[25] M. Razavi and F. Shams Aliee, "An Approach towards Enterprise Interoperability Assessment", Lecture Notes in Business Information Processing, vol. 38, part 1, pp. 52-65, 2009.

[26] M. Razavi Davoudi and F. Shams Aliee, "A New AHP-based Approach towards Enterprise Architecture Quality Attribute Analysis", In Proc. 3rd International Conference on Research Challenges in Information Science, Morocco, 2009, pp. 333-342.

[27] M. Razavi, F.Shams Aliee and K. Badie, "An AHP-based Approach toward Enterprise Architecture Analysis based on Enterprise Architecture Quality Attributes", Knowledge and Information Systems Journal, Springer London, vol. 28, no. 2, pp. 449-472, 2010.

[28] M. Razavi, F. Shams Aliee, and Amir E. Sarabadani Tafresh, "A Fuzzy AHP Based Approach Towards Enterprise Architecture Evaluation", In Proc. 3rd European Conference on Information Management and Evaluation, Sweden, 2009, pp. 408-422.

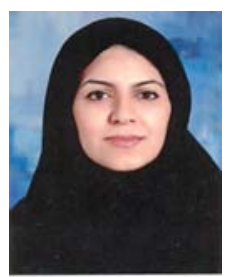

Mahsa Razavi Davoudi was borned in Tehran, Iran on February 1980. Mahsa earned her BSc in software engineering from Tehran University at 2001 and her MSc in the same field from Islamic Azad University, South Tehran Branch in 2004. In 2010, she earned her $\mathrm{PhD}$ in software engineering from Islamic Azad University, Science and Research Branch, Tehran and the subject of her thesis was "Enterprise Architecture Analysis based on Quality Attributes".

She has been working as Software Architect and Enterprise Architect in several projects. She is currently Member of faculty and Assistant Professor of Islamic Azad University, Central Tehran Branch. And also works as IT consultant. She has published several journal and conference papers. Her research interests are Enterprise Architecture, Service-oriented Architectures, Quality attributes, Assessment methods and Decision making.

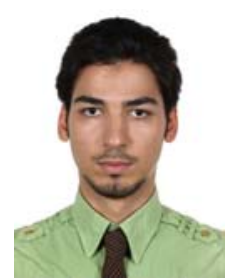

Kourosh Sheykhvand was born in Tehran, Iran on 29th of January in 1988. He earned her Bachelor of Science in software Engineering from Islamic Azad University, Central Tehran Branch, Tehran, Iran in 2010. Now, He is studying Master of Science in Engineering of computer systems, Politecnico di Milano, Milan, Italy.

He has worked in Ministry of Health and Medical Education, Tehran, Iran as a WEB DEVELOPER with ASP.Net, C\# and SQL Server. Also he was a co-author in the book: Operating system, simplification and classification concepts (Tehran, Iran, Andisheh Asatid, 2010). His research interests at the moment are EA, Software Engineering Methods and Databases. 